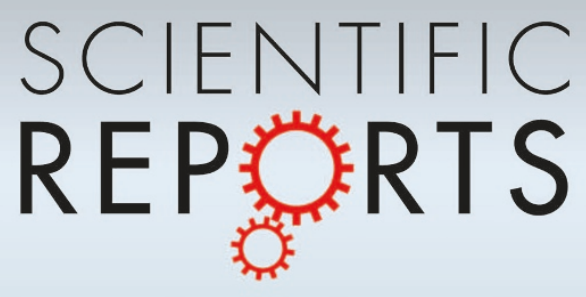

OPEN

SUBJECT AREAS:

SOLID-STATE CHEMISTRY

SYNTHESIS AND PROCESSING

NANOPARTICLES

BATTERIES

Received

27 May 2014

Accepted

27 June 2014

Published

14 July 2014

Correspondence and requests for materials should be addressed to H.P. (huanpangchem@ hotmail.com)

\section{Cobalt vanadium oxide thin nanoplates: primary electrochemical capacitor application}

\author{
Youjuan Zhang', Yuanying Liu', Jing Chen', Qifei Guo', Ting Wang' \& Huan Pang ${ }^{1,2}$
}

\begin{abstract}
${ }^{1}$ Key Laboratory for Clearer Energy and Functional Materials of Henan Province, College of Chemistry and Chemical Engineering, Anyang Normal University, Anyang, 455000 Henan, P.R. China, ${ }^{2}$ State Key Laboratory of Coordination Chemistry, Nanjing University, Nanjing, 210093, Jiangsu, P.R. China.
\end{abstract}

$\mathrm{Co}_{3} \mathrm{~V}_{2} \mathrm{O}_{8}$ thin nanoplates are firstly described as a kind of electrode material for supercapacitors. More importantly, from electrochemical measurements, the obtained $\mathrm{Co}_{3} \mathrm{~V}_{2} \mathrm{O}_{8}$ nanoplate electrode shows a good specific capacitance $\left(0.5 \mathrm{~A} \mathrm{~g}^{-1}, 739 \mathrm{~F} \mathrm{~g}^{-1}\right)$ and cycling stability $\left(704 \mathrm{~F} \mathrm{~g}^{-1}\right.$ retained after 2000 cycles). This study essentially offers a new kind of metal vanadium oxides as electrochemical active material for the development of supercapacitors.

\begin{abstract}
upercapacitors, an advanced safe electrochemical energy storage device, can hold higher power density, longer cycling life and shorter charge/discharge time $e^{1-9}$. The device stores energy on the basis of either charge accumulation (electric double layer capacitors) or fast reversible Faradaic reactions (pseudocapacitors) on the surface. Considerable efforts have been devoted to the development and characterization of new electrode materials with lower cost and improved performance.

Transition metal oxides can provide higher energy density in comparison to the electrical double layer capacitors with carbon-based active materials. And recently, binary metal oxides have been demonstrated better performance than single-component oxides due to their feasible oxidation states and high electrical conductivity $^{8,10-19}$. Transition metal vanadium oxides and vanadates have been widely investigated as possible active materials for rechargeable lithium batteries ${ }^{20-27}$. Very recently, Wang et al have reported the successful preparation of cobalt vanadium oxide $\left(\mathrm{Co}_{3} \mathrm{~V}_{2} \mathrm{O}_{8}\right)$ nanostructures which exhibit outstanding reversible capacity and excellent rate performance for lithium storage ${ }^{26}$. However, the exploitation of $\mathrm{Co}_{3} \mathrm{~V}_{2} \mathrm{O}_{8}$ nanostructures for supercapacitors has few developments.

This work describes the first investigation of $\mathrm{Co}_{3} \mathrm{~V}_{2} \mathrm{O}_{8}$ nanoplates for supercapacitors. We provide a facile and hydrothermal method to synthesize $\mathrm{Co}_{3} \mathrm{~V}_{2} \mathrm{O}_{8}$ nanoplates by the modified method of Wang et $\mathrm{al}^{26}$. Interestingly, the obtained $\mathrm{Co}_{3} \mathrm{~V}_{2} \mathrm{O}_{8}$ nanoplate electrode shows a good specific capacitance $\left(0.5 \mathrm{~A} \mathrm{~g}^{-1}, 739 \mathrm{~F} \mathrm{~g}^{-1}\right)$ and cycling stability (704 $\mathrm{F} \mathrm{g}^{-1}$ retained after 2000 cycles) for supercapacitors.
\end{abstract}

\section{Results}

XRD patterns of as-prepared samples were performed to reveal the phase of the as-prepared samples in Fig. 1a. All intense peaks shown in Fig. 1a can be well indexed to cubic $\mathrm{Co}_{3} \mathrm{~V}_{2} \mathrm{O}_{8}$ (JCPDS No.16-0675). The peaks are strong, which indicates the good crystallinity of the as-prepared samples. Good crystallinity of as-prepared $\mathrm{Co}_{3} \mathrm{~V}_{2} \mathrm{O}_{8}$ might be good to improve the cycle life of electrodes for its crystal structure is stable and it is not easy to be destroyed during the electrochemical process. The EDS result in Fig. $1 \mathrm{~b}$ demonstrates that the nanoplates are composed of the elements of $\mathrm{Co}, \mathrm{O}$, and $\mathrm{V}$.

The morphology of as-prepared $\mathrm{Co}_{3} \mathrm{~V}_{2} \mathrm{O}_{8}$ is examined by field emission scanning electron microscopy (FESEM), atomic force microscope (AFM) and transmission electron microscopy (TEM). A typical low-magnification FESEM image is shown in Fig. 2a and the morphology of samples is thin nanoplates in 2D microscale with a diameter of $150 \sim 200 \mathrm{~nm}$. The thickness of the thin nanosheet is $\sim 40 \mathrm{~nm}$ in Fig. $2 \mathrm{~b}$. AFM measurement is further used to confirm the thickness of the single nanoplate in Fig. 2c. It can be seen that the accurate thickness is $42.7 \mathrm{~nm}$ in the inset of Fig. 2c, which is consistent with the FESEM result in Fig. 2b. In addition, there are nearly no pores seen from the TEM image in Fig. 2d, e. The selected area electron diffraction (SAED) pattern is shown in the 

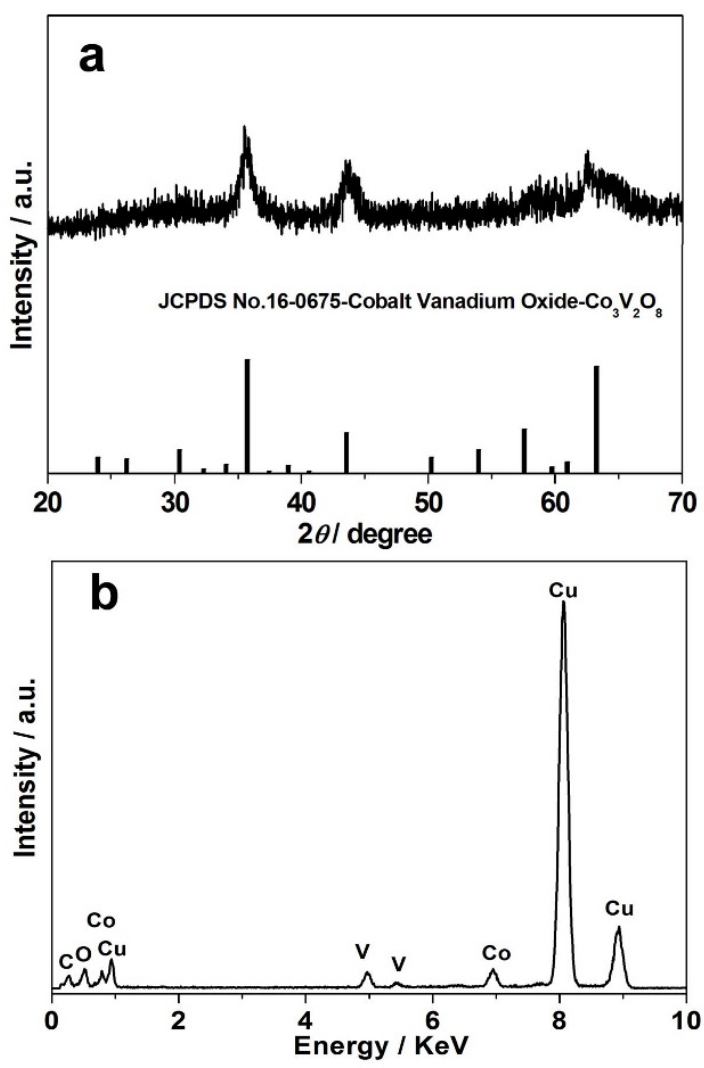

Figure $1 \mid$ a) XRD patterns of as-prepared samples and its corresponding JCPDS card No 16-0675; b) corresponding EDS patterns.

inset of Fig. 2e, which demonstrates the good crystalline nature of the product. The measured distance of neighboring lattice fringes in Fig. $2 \mathrm{f}$ is $\sim 0.59 \mathrm{~nm}$, corresponding well to the (110) lattice spacing of $\mathrm{Co}_{3} \mathrm{~V}_{2} \mathrm{O}_{8}$.

\section{Discussion}

The CVs of $\mathrm{Co}_{3} \mathrm{~V}_{2} \mathrm{O}_{8}$ thin nanoplate electrodes (a mass loading of $\sim 5 \mathrm{mg})$ in $3.0 \mathrm{M} \mathrm{KOH}$ at different scan rates $\left(5 \sim 100 \mathrm{mV} \mathrm{s}^{-1}\right)$ are shown in Fig. 3a. As is seen in Fig. 3a, the shapes are different from that of electric double-layer capacitance, suggesting that the capacity mainly results from pseudocapacitive capacitance. And it is clear that the Faradaic pseudocapacitive property of $\mathrm{Co}_{3} \mathrm{~V}_{2} \mathrm{O}_{8}$ thin nanoplates is based on the surface redox mechanism of $\mathrm{Co}^{2+}$ to $\mathrm{Co}^{3+}$ on the surface. Chronopotentiometry (CP) curves at different current densities are shown in Fig. 3b. Different charge-discharge current densities and times can be clearly seen. As increasing of current densities, short charge-discharge times have been obtained.

The relationship between the specific capacitances calculated by $\mathrm{CP}$ curves and current densities is given in Fig. 3c. Based on the curve, $\mathrm{Co}_{3} \mathrm{~V}_{2} \mathrm{O}_{8}$ thin nanoplate electrodes show a good specific capacitance and reach up to $739 \mathrm{~F} \mathrm{~g}^{-1}$ at the current density of $0.5 \mathrm{~A} \mathrm{~g} \mathrm{~g}^{-1}$, and $516 \mathrm{~F} \mathrm{~g}^{-1}$ even at $4.0 \mathrm{~A} \mathrm{~g}^{-1}$. The specific capacitance of $\mathrm{Co}_{3} \mathrm{~V}_{2} \mathrm{O}_{8}$ thin nanoplates is better than that of our previous cobalt based phosphate nanomaterials, for example, $\mathrm{NH}_{4} \mathrm{CoPO}_{4} \cdot \mathrm{H}_{2} \mathrm{O}$ microflowers $\left(<340 \mathrm{~F} \mathrm{~g}^{-1} \text { at } 1.5 \mathrm{~A} \mathrm{~g}^{-1}\right)^{28}$, cobalt phosphite microarchitectures $\left(<312 \mathrm{~F} \mathrm{~g}^{-1} \text { at } 1.5 \mathrm{~A} \mathrm{~g}^{-1}\right)^{29}$. However, some materials show larger values than that of ours ${ }^{30,31}$

The relationship of the specific capacitance against cycling number of $\mathrm{Co}_{3} \mathrm{~V}_{2} \mathrm{O}_{8}$ thin nanoplate electrodes is shown in Fig. 3d, which shows its good specific capacitance retention at $0.5 \mathrm{~A} \mathrm{~g}^{-1}$. After 350 continuous charge-discharge cycles, $\mathrm{Co}_{3} \mathrm{~V}_{2} \mathrm{O}_{8}$ thin nanoplate electrodes almost retain the same specific capacitance as its initial value. More importantly, $\mathrm{Co}_{3} \mathrm{~V}_{2} \mathrm{O}_{8}$ thin nanoplate electrodes still retain more than $95.3 \%$ of their specific capacitance after 2000 continuous charge-discharge cycles. After the testing of the cycle life, we have measured the morphology and X-ray diffraction of the electrode materials in Supplementary Information (SI) Fig. 1, 2. There are few changes of $\mathrm{Co}_{3} \mathrm{~V}_{2} \mathrm{O}_{8}$ thin nanoplates after 2000 charge-discharge cycles in SI Fig. 1, and the good crystallinity of as-prepared $\mathrm{Co}_{3} \mathrm{~V}_{2} \mathrm{O}_{8}$ has also been maintained. What's more, the nanoplate structure might offer a stable structure for ion intercalation/extraction, which might improve the cycle life of the electrode.
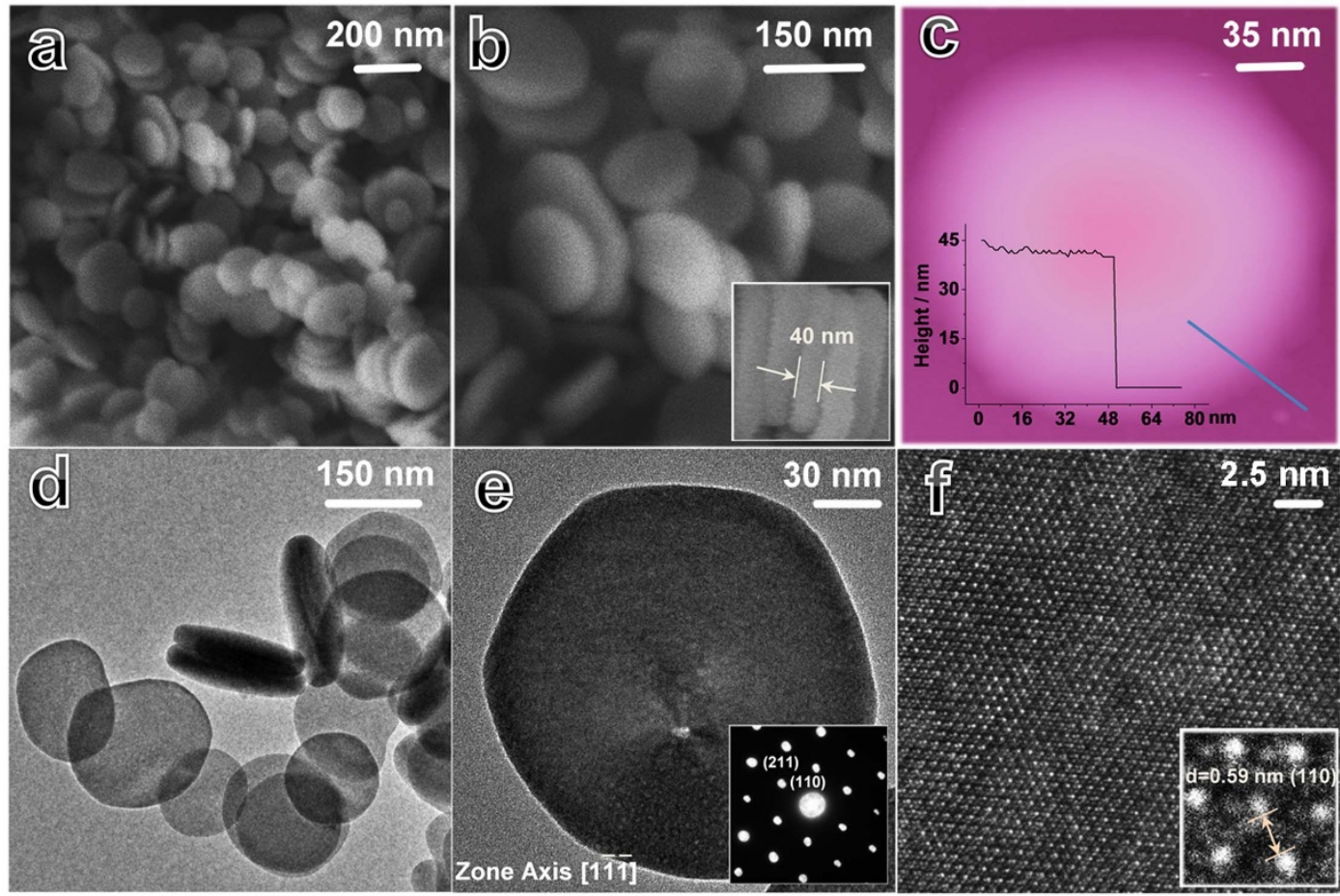

Figure $2 \mid$ a, b) FESEM images of as-prepared $\mathrm{Co}_{3} \mathrm{~V}_{2} \mathrm{O}_{8}$; c) Corresponding AFM image; d, e) TEM images (inset-corresponding SAED pattern); f) Corresponding HRTEM image (inset-the large magnification image). 

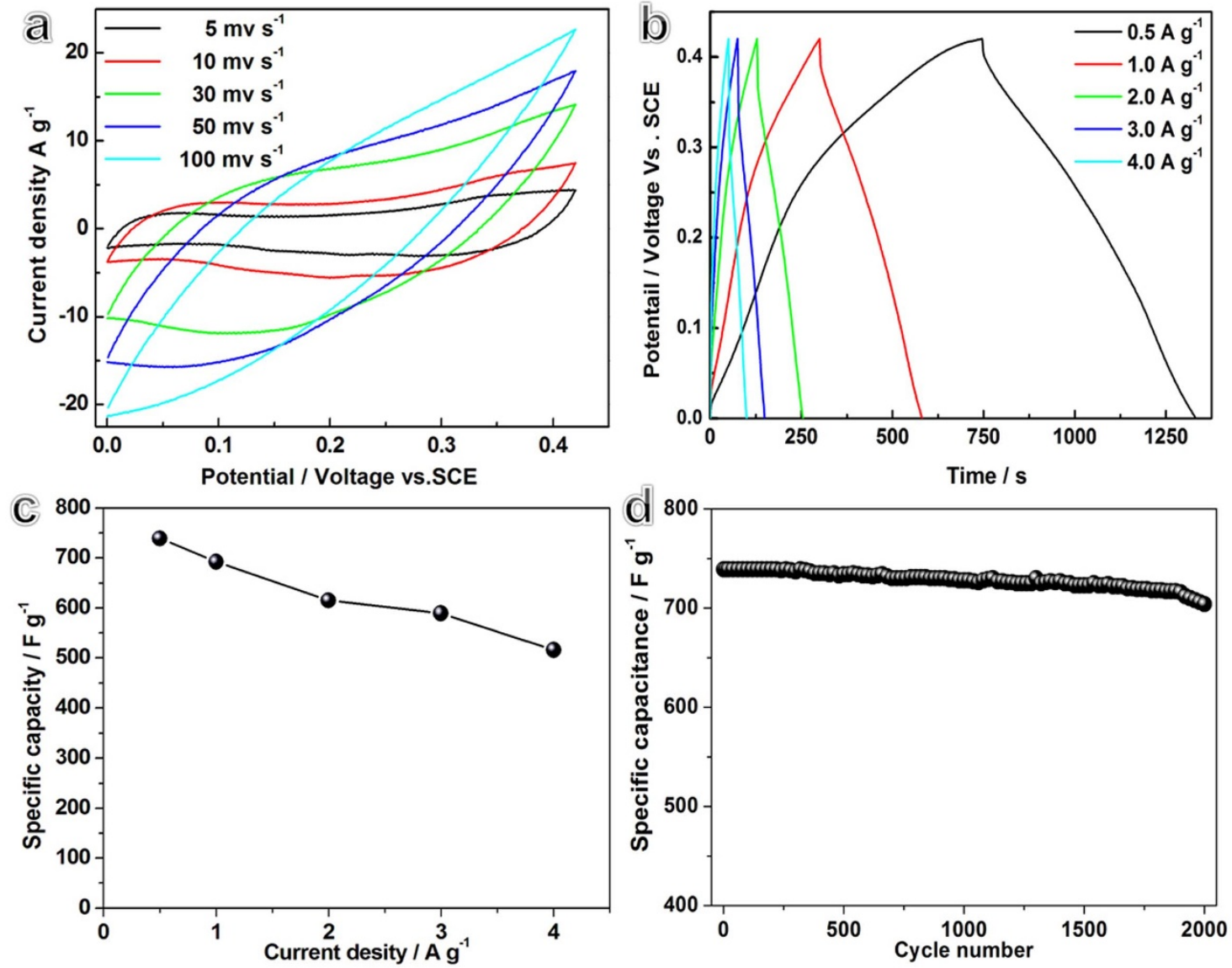

Figure $3 \mid$ a) Cyclic voltammetry within a $0.0-0.42 \mathrm{~V}$ range at a scan rate 5-100 mV s sere performed on the $\mathrm{Co}_{3} \mathrm{~V}_{2} \mathrm{O}_{8}$ thin nanoplate electrode in 3.0 $\mathrm{M} \mathrm{KOH}$ at room temperature, b) The galvanostatic charge-discharge curves during current densities, $0.5-4.0 \mathrm{~A} \mathrm{~g} \mathrm{~g}^{-1}$, c) Specific capacitances derived from the discharging curves at the current density of 0.5-4.0 $\mathrm{A} \mathrm{g}^{-1}$, and d) Charge/discharge cycling test at $0.5 \mathrm{~A} \mathrm{~g}^{-1}$.

$$
\mathrm{Co}_{3} \mathrm{~V}_{2} \mathrm{O}_{8}+6 \mathrm{OH}-=3 \mathrm{CoOOH}+\mathrm{H}_{3} \mathrm{~V}_{2} \mathrm{O}_{8}^{-3}+3 \mathrm{e}^{-}
$$

We have tried to propose the possible the reaction mechanism of $\mathrm{Co}_{3} \mathrm{~V}_{2} \mathrm{O}_{8}$ in equation (1). To identify the exact electrical conductivity of electrodes, we have measured electrochemical impedance spectra (EIS) of $\mathrm{Co}_{3} \mathrm{~V}_{2} \mathrm{O}_{8}$ thin nanoplate electrodes at room temperature in the frequency range $0.01-10^{5} \mathrm{~Hz}$ at different potentials in SI Fig. 4. The impedance plot at $0.42 \mathrm{~V}$ in $3 \mathrm{M} \mathrm{KOH}$ exhibits a line along the imaginary axis $\left(Z^{\prime \prime}\right)$. At a potential of $0,0.60$ or $0.70 \mathrm{~V}$, the linear characteristic becomes weaker. Thus, the proper potential range, over which electrode can generate desirable capacitance, is below $0.42 \mathrm{~V}$. Fig. 4 shows the EIS of $\mathrm{Co}_{3} \mathrm{~V}_{2} \mathrm{O}_{8}$ thin nanoplate electrodes at room temperature and its calculated curve by the ZSimpWin software. An equivalent circuit used to fit the impedance curve is given in the inset of Fig. $4 \mathrm{a}$, which is similar to the circuit employed for the working electrode of supercapacitors. The EIS data can be fitted by a bulk solution resistance $R_{s}$, a charge-transfer $R_{c t}$ and a pseudocapacitive element $C_{p}$ from the redox process of electrode materials, and a CPE to account for the double-layer capacitance. The charge-transfer resistance $R_{c t}$ is calculated by the ZSimpWin software. From the calculated results, $R_{c t}$ of $\mathrm{Co}_{3} \mathrm{~V}_{2} \mathrm{O}_{8}$ thin nanoplate electrodes is $5.3 \Omega$. It clearly demonstrates the reduced charge-transfer resistance of the $\mathrm{Co}_{3} \mathrm{~V}_{2} \mathrm{O}_{8}$ thin nanoplate electrode. The nanoplate surface-interface character might decrease the polarization of the electrode, and thus increase the capacity. What's more, the phase angles for impedance plots of $\mathrm{Co}_{3} \mathrm{~V}_{2} \mathrm{O}_{8}$ thin nanoplate electrodes and its calculated curve by ZSimpWin software are observed in Fig. $4 \mathrm{~b}$. These phase angles are near $80^{\circ}$ in the low frequencies clearly, which means that the $\mathrm{Co}_{3} \mathrm{~V}_{2} \mathrm{O}_{8}$ thin nanoplates allow ions or electrolyte transfer to occur quickly. Compared with the charge-transfer resistance of other $\mathrm{Co}_{3} \mathrm{~V}_{2} \mathrm{O}_{8}$ nano/micro structures in SI Fig. 3, 4, and SI Table 1, it is seen that the $\mathrm{Co}_{3} \mathrm{~V}_{2} \mathrm{O}_{8}$ thin nanoplate can reduce the charge-transfer resistance more effective than other $\mathrm{Co}_{3} \mathrm{~V}_{2} \mathrm{O}_{8}$ nano/micro structures.

In summary, $\mathrm{Co}_{3} \mathrm{~V}_{2} \mathrm{O}_{8}$ thin nanoplates have been successfully synthesized to show the novel nanoplate surface-interface feature, which plays a key role in the ion intercalation/extraction and electrolyte access. The electrochemical investigation of $\mathrm{Co}_{3} \mathrm{~V}_{2} \mathrm{O}_{8}$ thin nanoplates is interesting work, which firstly illustrates $\mathrm{Co}_{3} \mathrm{~V}_{2} \mathrm{O}_{8}$ thin nanoplates can be applied as an electroactive material for supercapacitors. Despite the specific capacitance of $\mathrm{Co}_{3} \mathrm{~V}_{2} \mathrm{O}_{8}$ thin nanoplates are not much larger than some famous materials, it might direct a new generation of nanodevices by exploring the electrochemical characteristics of novel nano/micromaterials.

\section{Methods}

In a typical synthesis, $187 \mathrm{mg}$ of $\mathrm{NH}_{4} \mathrm{VO}_{3}$ was dissolved into $32 \mathrm{~mL}$ deionized water at $80^{\circ} \mathrm{C}$. Under severely stirring, $40 \mathrm{mg} \mathrm{NaOH}$ was added to the ammonium metavanadate solution. Then, $76 \mathrm{mg} \mathrm{Co}(\mathrm{OAc})_{2} \cdot 4 \mathrm{H}_{2} \mathrm{O}$ was added to the solution under stirring. After continuous stirring for 10 mins, the resulting yellow precursor suspension was transferred into a $40 \mathrm{~mL}$ Teflon-lined autocalve and maintained at $120^{\circ} \mathrm{C}$ for 12 hours. After reaction, the brown yellow precipitates were obtained. The precipitates were thoroughly washed with distilled water and ethanol to remove ions possibly remaining in the final products, and dried at room temperature in the air.

Characterizations. The morphology of as-prepared samples was observed by a JEOL JSM-6701F field-emission scanning electron microscope (FE-SEM) at an acceleration voltage of $5.0 \mathrm{kV}$. The phase analyses of the samples were performed by $\mathrm{X}$-ray diffraction (XRD) on a Rigaku-Ultima III with $\mathrm{Cu} \mathrm{K}_{\alpha}$ radiation $(\lambda=1.5418 \AA)$. Transmission electron microscopy (TEM) images were captured on the JEM-2100 instrument microscopy at an acceleration voltage of $200 \mathrm{kV}$. Atomic force microscope (AFM) images were measured at CSPM4000 (Benyuan, Beijing).

Electrochemical measurement. Electrochemical study on $\mathrm{Co}_{3} \mathrm{~V}_{2} \mathrm{O}_{8}$ thin nanoplates electrodes was carried out on a CHI 660D electrochemical working station (Shanghai 

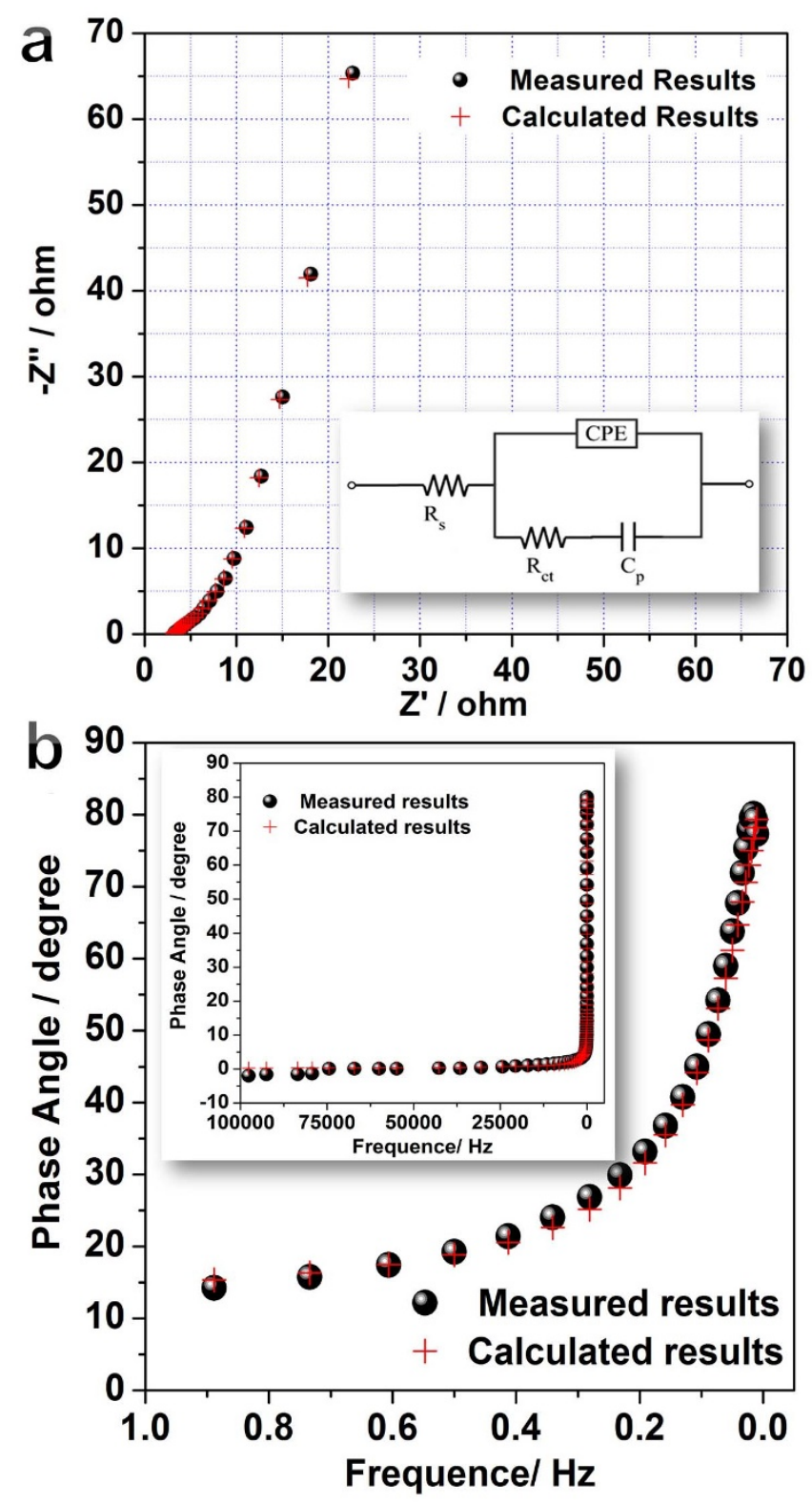

Figure $4 \mid$ The EIS of the electrodes at room temperature and its corresponding calculated curve, in inset of a) The equivalent circuit; and b) The phase angles for impedance plots and its corresponding calculated curve.

Chenhua Instrument, Inc.). All electrochemical performances were carried out respectively in a conventional three-electrode system equipped with a platinum electrode and a saturated calomel electrode (SCE) as counter and reference electrodes. Before electrochemical measurement, we have purged out $\mathrm{O}_{2}$ from the solution by the inert gas-Ar. The working electrode was made by mixing active materials $\left(\mathrm{Co}_{3} \mathrm{~V}_{2} \mathrm{O}_{8}\right.$ thin nanoplates), acetylene black, and PTFE (polytetrafluoroethylene) at a weight ratio of $80: 15: 5$, coating on a piece of foamed nickel foam of about $1 \mathrm{~cm}^{2}$, and pressed it to be a thin foil at the pressure of 5.0 MPa. The electrolyte was $3.0 \mathrm{M} \mathrm{KOH}$ solution. Electrochemical impedance spectroscopy measurements of all the samples were conducted at $0.42 \mathrm{~V}$ in the frequency range from $100 \mathrm{kHz}$ to $0.01 \mathrm{~Hz}$ with the AC voltage amplitude of $5 \mathrm{mV}$ by using PARSTAT2273.

1. Conway, B. E. Electrochemical supercapacitors: scientific fundamentals and technological applications. Conway, B. E. (ed.), 1-10 (Plenum Publishing; New York, 1999).

2. Mai, L. Q. et al. Synergistic interaction between redox-active electrolyte and binder-free functionalized carbon for ultrahigh supercapacitor performance. Nat. Commun. 4, 2923 (2013).

3. Mai, L. Q. et al. Fast ionic diffusion-enabled nanoflake electrode by spontaneous electrochemical pre-intercalation for high-performance supercapacitor. Sci. Rep. 3, 1718 (2013).
4. Wang, Y. G., Li, H. Q. \& Xia, Y. Y. Ordered whiskerlike polyaniline grown on the surface of mesoporous carbon and its electrochemical capacitance performance. Adv. Mater. 18, 2619-2623 (2006).

5. Wang, Y. G., Wang, Z. D. \& Xia, Y. Y. An asymmetric supercapacitor using $\mathrm{RuO}_{2} /$ $\mathrm{TiO}_{2}$ nanotube composite and activated carbon electrodes. Electrochimica Acta 50, 5641-5646 (2005)

6. Zhu, D. D., Wang, Y. D., Yuan, G. L. \& Xia, H. High-performance supercapacitor electrodes based on hierarchical Ti@ $\mathrm{MnO}_{2}$ nanowire arrays. Chem Commun. 50, 2876-2878 (2014).

7. Xia, X. F. et al. Nanostructured ternary composites of graphene $/ \mathrm{Fe}_{2} \mathrm{O}_{3} /$ polyaniline for high-performance supercapacitors. J. Mater. Chem. 22, 16844-16850 (2012).

8. Yuan, C. Z., Wu, H. B., Xie, Y. \& Lou, X. W. Mixed transition-metal oxides: Design, synthesis, and energy-related applications. Angew. Chem. Int. Ed. $\mathbf{5 3}$, 1488-1504 (2014).

9. Liu, C., Li, F., Ma, L. P. \& Cheng, H. M. Advanced materials for energy storage. Adv. Mater. 22, E28-E62 (2010).

10. Ozolins, V., Zhou, F. \& Asta, M. Ruthenia-Based Electrochemical Supercapacitors: Insights from First-Principles Calculations. Acc. Chem. Res. 46, 1084-1093 (2013).

11. Wei, T. Y. et al. Cobalt oxide aerogels of ideal supercapacitive properties prepared with an epoxide synthetic route. Chem. Mater. 21, 3228-3233 (2009).

12. $\mathrm{Du}, \mathrm{X}$. et al. Electrochemical performances of nanoparticle $\mathrm{Fe}_{3} \mathrm{O}_{4} /$ activated carbon supercapacitor using $\mathrm{KOH}$ electrolyte solution. J. Phys. Chem. C 113, 2643-2646 (2009).

13. Yuan, C. Z. et al. Ultrathin mesoporous $\mathrm{NiCo}_{2} \mathrm{O}_{4}$ nanosheets supported on $\mathrm{Ni}$ foam as advanced electrodes for supercapacitors. Adv. Funct. Mater. 22, 4592-4597 (2012).

14. Zhang, G. Q. \& Lou, X. W. Controlled Growth of $\mathrm{NiCo}_{2} \mathrm{O}_{4}$ Nanorods and Ultrathin Nanosheets on Carbon Nanofibers for High-performance Supercapacitors. Sci. Rep. 3, 1470 (2013).

15. Zhang, G. Q. et al. Single-crystalline $\mathrm{NiCo}_{2} \mathrm{O}_{4}$ nanoneedle arrays grown on conductive substrates as binder-free electrodes for high-performance supercapacitors. Energy Environ. Sci. 5, 9453-9456 (2012).

16. Karthikeyan, K., Kalpana, D. \& Renganathan, N. G. Synthesis and characterization of $\mathrm{ZnCo}_{2} \mathrm{O}_{4}$ nanomaterial for symmetric supercapacitor applications. Ionics 15, 107-110 (2009).

17. Bao, L. H., Zang, J. F. \& Li, X. D. Flexible $\mathrm{Zn}_{2} \mathrm{SnO}_{4} / \mathrm{MnO}_{2}$ Core/Shell NanocableCarbon Microfiber Hybrid Composites for High-Performance Supercapacitor Electrodes. Nano Lett. 11, 1215-1220 (2011).

18. Yu, X. Z., Lu, B. G. \& Xu, Z. Super Long-Life Supercapacitors Based on the Construction of Nanohoneycomb-Like Strongly Coupled $\mathrm{CoMoO}_{4}-3 \mathrm{D}$ Graphene Hybrid Electrodes. Adv. Mater. 7, 1044-1051 (2014).

19. Mai, L. Q. et al. Hierarchical $\mathrm{MnMoO}_{4} / \mathrm{CoMoO}_{4}$ heterostructured nanowires with enhanced supercapacitor performance. Nature Commun. 2, 318 (2011).

20. Takeuchi, K. J. et al. Silver vanadium oxides and related battery applications. Coord. Chem. Rev. 219-221, 283-310 (2001).

21. Denis, S. et al. ${ }^{57} \mathrm{Fe}$ Mössbauer study of the electrochemical reaction of lithium with triclinic iron vanadate. Chem. Mater. 12, 3733-3739 (2000).

22. Patoux, S. \& Richardson, T. J. Lithium insertion chemistry of some iron vanadates. Electrochem. Commun. 9, 485-491 (2007).

23. Ichikawa, S. N., Hibino, M. \& Yao, T. Structural Change Induced by Electrochemical Lithium Insertion in Cobalt Vanadium Oxide Batteries and Energy Storage. J. Electrochem. Soc. 154, A1156-A1159 (2007).

24. Lei, S. J., Tang, K. B., Jin, Y. \& Chen, C. H. Preparation of aligned $\mathrm{MnV}_{2} \mathrm{O}_{6}$ nanorods and their anodic performance for lithium secondary battery use. Nanotechnology 18, 175605 (2007).

25. $\mathrm{Ma}, \mathrm{H}$. et al. $\alpha-\mathrm{CuV}_{2} \mathrm{O}_{6}$ nanowires: Hydrothermal synthesis and primary lithium battery application. J. Am. Chem. Soc. 130, 5361-5367 (2008).

26. Yang, G., Cui, H., Yang, G. W. \& Wang, C. X. Self-assembly of $\mathrm{Co}_{3} \mathrm{~V}_{2} \mathrm{O}_{8}$ multilayered nanosheets: Controllable synthesis, excellent Li-Storage Properties, and Investigation of Electrochemical Mechanism. ACS Nano DOI: 10.1021/ nn406449u (2014).

27. Cheng, F. Y. \& Chen, J. Transition metal vanadium oxides and vanadate materials for lithium batteries. J. Mater. Chem. 21, 9841-9848 (2011).

28. Pang, $\mathrm{H}$. et al. Facile fabrication of $\mathrm{NH}_{4} \mathrm{CoPO}_{4} \cdot \mathrm{H}_{2} \mathrm{O}$ nano/microstructures and their primarily application as electrochemical supercapacitor. Nanoscale $\mathbf{4}$, 5946-5953 (2012).

29. Pang, H. et al. Cobalt phosphite microarchitectures assembled by ultralong nanoribbons and their application as effective electrochemical capacitor electrode materials. Nanoscale 5, 503-507 (2013).

30. Wu, H. B., Pang, H. \& Lou, X. W. D. Facile synthesis of mesoporous $\mathrm{Ni}_{0.3} \mathrm{Co}_{2.7} \mathrm{O}_{4}$ hierarchical structures for high-performance supercapacitors. Energy Environ. Sci. 6, 3619-3626 (2013).

31. Yang, Q. et al. Ultrathin $\mathrm{Co}_{3} \mathrm{O}_{4}$ nanosheet arrays with high supercapacitive performance. Scientific Reports 3, 3537-3543 (2013)

\section{Acknowledgments}

This work is supported by the Program for New Century Excellent Talents of the University in China (grant no. NCET-13-0645) and National Natural Science Foundation of China (NSFC-21201010), Program for Innovative Research Team (in Science and Technology) in 
University of Henan Province (14IRTSTHN004), the Science \& Technology Foundation of Henan Province (122102210253, 13A150019), and the China Postdoctoral Science Foundation (2012M521115). We are very grateful to Liang Chen from Anyang Normal University in the language modification.

\section{Author contributions}

Y.J.Z., Y.Y.L., J.C., Q.F.G., T.W. and H.P. conceived and designed the experiments., Y.J.Z., J.C. and H.P. analyzed the measurements. H.P. wrote the manuscript in collaboration with all the authors.

\section{Additional information}

Supplementary information accompanies this paper at http://www.nature.com/ scientificreports
Competing financial interests: The authors declare no competing financial interests. How to cite this article: Zhang, Y.J. et al. Cobalt vanadium oxide thin nanoplates: primary electrochemical capacitor application. Sci. Rep. 4, 5687; DOI:10.1038/srep05687 (2014).

(c) (i) (\$) This work is licensed under a Creative Commons Attribution-NonCommercialNoDerivs 4.0 International License. The images or other third party material in this article are included in the article's Creative Commons license, unless indicated otherwise in the credit line; if the material is not included under the Creative Commons license, users will need to obtain permission from the license holder in order to reproduce the material. To view a copy of this license, visit http:// creativecommons.org/licenses/by-nc-nd/4.0/ 